\title{
Asymmetric Changes in the World Economy
}

\author{
Ulviyya Rzayeva \\ (Department of Information Economy and Technologies/Azerbaijan State University of Economics, Baku)
}

\begin{abstract}
This study focuses on the investigation of the problems caused by the developing asymmetry of economic relations in the global context. The relevance of the study is dictated by the contradictions between existing practice of asymmetric economic society and an ongoing domination of "equilibrium" paradigm in economic theory that denies the necessity of asymmetry of economic development and emphasizes only its "negative" character. In the authors' opinion, the current world situations show that development of the global economy has the following tendency: the current asymmetry of political influence in the transatlantic region and digital technologies smoothly moving to developing countries are quite destructive to the current methods of providing the stable economy. Key signs indicate that the center of economic development's gravity is shifting to developing countries.
\end{abstract}

Keywords: Asymmetries of global development; innovations; cycles; technologies; transformations

\section{Introduction}

In XX century, interest in problems of the unevenness of economic development was largely due to the problems of world economy's formation, which included the problem of developing countries [1]. Thus, the number of autarkic "theories of backwardness" were created within the framework of neo-Keynesian direction, described in the works of Domar [2], Nelson [3], Leibenstein [4], Rostow [5] and etc. In these researches, the gap in the levels of development was driven by low degree of self-reproducing equilibrium in developing countries. Neo-Keynesians suggested that removal of the system from this state of equilibrium would cause the transition to self-sustaining growth and finally reduce the gap in economic development levels. Hirschman [6] offered the concept of misbalanced growth, based on the fact that misbalance in the economic system was the stimulus for investment, and thus, its maintenance would lead to economic growth in developing countries.

Supporters of neoliberalism advocate the principle of self-regulation, free from an excessive legislation. Until recently, this stream was considered as universal remedy for economic development, but today it does not consider conditions and specifics of developing countries. Under the pretext of "correction" of developing countries' economy (according to standard "recipe": liberalization of the prices and finance, privatization, ensuring full openness of the markets and their orientation to export, guarantees of export of profits and etc.) the actual desovereignization of these countries and imposing them to the certain place in the global economy are carried out [7]. The leading idea of neoliberalism can be formulated as follows - the intensification and the world distribution of free market both extensively that is by international scale, and intensively that is affecting all spheres of society life. Thus, neoliberalism shows basic relationship with globalization, especially in the economic sphere.

Globalization began to be actively studied from 1990th, resulting in creation of the whole new directions of modern economic science and the theories of the international relations. In the context of this research it would be desirable to distinguish J.-M. Siroen's [8] manuscripts in terms of clarification of globalization's essence. The author investigated many asymmetric aspects of international economic relations based on this difficult phenomenon. Having contradictory and asymmetric character, globalization acts as the catalyst of the conflicts and financial and economic crises. Enlarging gap between poorest and richest countries forms and increases global asymmetries not only in economy; this phenomenon is typical for many spheres of public life - educational, scientific and cultural. Interesting views of how the principles of globalization in some way discriminate not only developing states are offered in Kacowicz's [9] paper. A large part of the population in OECD countries also suffers from the effects of an unbalanced globalization policy, facing the problems of economic inequality. However, contradictions and asymmetries of global economic development have one very important aspect: it is the source of continuous progress of world economic system. From such point of view significant functions of economic development's asymmetry are distributive (determination of public product's distribution parameters), differentiating (differentiation of producers and consumers), integrative-disintegrative (integration of the isolated systems into uniform economic system and destruction of the old ones), stimulatingdestimulating (simultaneous stimulation and limiting of economic growth) functions. 


\section{The Review Of World Economy In Terms Of Asymmetry}

The national economy within the framework of world economy and international economic relations in the late XX - early XXI century were characterized by asymmetry of their state and development. This was reflected primarily in intensification of inequalities between them. Market reforms in the transitional economies of post-Soviet countries have contributed to strengthening the asymmetry in the states and development of national economies all over the world. Systemic transformational crisis of 90-ies of the XX century, both quantitatively and qualitatively changed places of post-Soviet countries in the world, sending them far back. The successful development of China's economy on the background of the transformational crisis of post-Soviet countries' economies also reinforces the asymmetry of the global economy. Even within the limits of separate, especially large multinational countries (India, etc.) homogeneity of the economy is practically absent and there is an asymmetry in its development. It concerns also the sustainable regional community like the European Union.

In the second half of the twentieth century we saw the classic version of the N. Kondratieff's long wave cycle, when developed countries dominated in the global economy. 1990s were the era of unlimited dominance of the "Washington Consensus" - the liberal Western model, however, the collapse of the "Washington" economies in Latin America and the rapid development of countries that use the model "of authoritarian growth" led to unpredictable consequences. So, almost all the 2000s were marked by "dispute" between Washington and Beijing consensus - in essence, between the west ultra-liberal and authoritarian models of the Chinese economy. However, it seems that because of this dispute the first paradigm loses - upon closer inspection the global economy starts moving along the path away from Washington.

In the beginning of the XXI century in the rising wave of modern big cycle there were significant changes caused by fundamental shifts in the world economy. China's and other large developing countries' weights have risen sharply in the world GDP [10]. Developing countries have become the locomotives of modern economic development with higher rates return and investments in fixed capital.

In 1996-2013 labor productivity in developed countries increased faster than GDP per capita and thus unemployment was also increasing here. In contrast to the rising wave of the second half of the XX century, after 1995 the proportion of high-tech industries in the GDP of developed countries declined. This is due to the features of ICT's development. We become witnesses of the next asymmetry: production of the leaders of scientific and technological progress indeed is growing many times faster than GDP, but prices are falling rapidly. In ICT, the dominance of technological branches of scientific and technical progress are associated with the enhancement of production methods over engineering. This fact leads to creation of new technologies which in turn leads to the release of workforce and results in increasing unemployment.

\section{Technological Innovations Introduced Into Markets By Developed Countries As Drivers Of Developing Countries. Four Reasons For Asymmetry: Displacement Of The Center Of Gravity To Developing Countries}

Over the last decades structural shifts in world economy considerably changed the role of innovations in economic development of the countries. The successful development of any company or government, as well as their prosperity in the competition is inseparably linked to new inventions - innovations and their continuous implementation. Despite visible progress in developing countries in recent decades, currently they significantly lag behind developed. At the same time developed countries under the influence of endogenous and exogenous factors lose their advantages. The authors consider four reasons for this in terms of global asymmetry in the following foreshortenings.

\subsection{The competition in the directions: the USA - the EU, Western Europe - Eastern Europe, Northern Europe - Southern Europe, developed countries - developing countries}

The United States maintains its claim to be the leading world power, as the first among equals. Consequently, dialogue on equal rights between the US and the EU which is so desired by Europeans will be based solely on interdependence, that is, on mutual dependence, and assumes asymmetrical distribution of forces. In spite of joined domestic market and the existing legal frameworks, Member States have difficulties in coordinated action and, as a rule, they take protectionist measures. This remedies work against the interests of other countries outside the EU. In the field of "soft" strength and economy, Europe has much to offer, but this is not sufficient to create the symmetrical relationship or partnership between equals. Different studies suggest that the political and economic importance of Europe will be reduced [11]. In [12] tendencies of transatlantic asymmetry are investigated in detail. This fact leads to demographic changes and displacements of the economic center of gravity to Asia [13].

For support of the aforesaid argument we will provide the theorem of predefinitions [14]. In accordance with the terms of this theorem the competition between the two countries on two fronts is considered: economic and social efficiency. One country leads on the first front, another - on the second. This situation determines the 
following mechanism of competition between two countries adhering to the symmetrical strategy: one of them endeavors to maintain its advantages in the field of economic efficiency simultaneously trying to catch up with competitors in terms of social achievements; other is attempt to fix its social model on the background of the race for the leadership in the field of economy. Thus, each country carries out large-scale borrows from its opponent.

Let us consider the pair of USA - Europe. The US outruns the EU by economic efficiency, and the European social model is more effective and attractive. But hardly the sympathy of people on the "Swedish socialism" can lead to the defeat of America. Theorem about predefinition tells us that Europe is doomed to failure. In fact, Europe as the world leader is a utopia, as the Soviet Union in due time. The primacy of wealth will lead to the fact that the States will naturally take over social achievements of the EU, while the latter have to overstrain constantly for keeping its social benefits. And in this case, there can be no competition, whereas the economy and society develop only through competition.

What can we say about asymmetries in the pair Western Europe - Eastern Europe? In the context of this study we'll consider the asymmetry between national economies within the EU on the example of exports from the East to the West of Europe. [15] explores how European financial integration was conducted and focuses on exports between Central and Eastern European countries during 1994-2013. The results show that the development of stock markets and the banking sector leads to more negative than to positive influence on exports. The negative effect of the bank credit is explained by lack of the bank loans to increase export, despite the support of EU bank.

Let us consider the phenomenon of price asymmetry - so-called "rockets and feathers" - distortion of competition in the retail market. Following this phenomenon, we see that when oil prices rise, petrol rate at gas stations flies up with a rocket speed, whereas when oil falls - the prices fall very slowly. It was found that there is an asymmetry of internal and international prices between majorities of the EU Member States. Upward trends in world prices are transmitted to national markets without special delays and with high degree of correlation; and vice versa the downward trends in world prices operate with considerable delay and with lesser extent of interdependence. The conditions of competition in the national markets, including the lack of nondiscriminatory access to infrastructure and logistics may act as the reasons for this asymmetry. Empirical results in [16] reflect two stable models: firstly, the influence of exchange rate fluctuations shows its positive asymmetry (i.e., depreciation has a greater effect than appreciation). Developing economies widely use the effects of the weakening of their currencies. Smooth devaluation of national currency against the currencies dominating in the external economic turn is capable to stimulate export growth. As a result, there is a growing interest in export production; there is an opportunity to reduce prices in foreign markets, to occupy new product and customer niches. Fluctuations in prices of crude oil induces negative asymmetry (i.e. reduction in prices of crude oil has bigger effect than increase in prices). Secondly, positive asymmetry of changes of an exchange rate is stronger shown in the key countries of the Eurozone. Various behaviors between the kernel and the periphery of the Eurozone give better understanding of the nature of price asymmetry.

Moving to the Northern Europe - Southern Europe direction, we observe the integrative-disintegrative role of asymmetry: between the decision making, its implementation and the results of implementation there are time intervals (logs), which can also lead to "failures" of the government. In this regard, it is important to remember the law of unforeseen consequences: in the issue of any activities, either the desired result is not achieved, or is achieved with big expenses or the opposite result is achieved. Eventually interaction of the state and the market leads to simultaneous modification of both mechanisms. So, integration of the market-specific standards of economic behavior into government institution influences the market development. This allows solving some problems faster and more efficiently through compromise solutions. The results demonstrate a symmetric adjustment process for the Northern Europe and asymmetric for the Southern Europe, when stock prices and industrial products adapt for achieving the long-term equilibrium. The main reason for asymmetry is the differences in structural competitiveness, which is the weakest link of the South relatively to the North. [17] emphasize to the possible relationships between supply shocks and the profitability of financial markets based on the same general equilibrium model. Authors give the price of oil as an example of similar shock. According to the conclusions obtained by authors on the basis of this model, positive shock of the offer (increase in prices) leads to the deterioration in conditions in trade and to growth of the foreign stock markets. In [18] the interrelation between stock prices of industrial companies and industrial production in the South and the North of the Eurozone during 2004-2013 is investigated. Unlike previous studies, this investigation defines additional price interaction and dynamics that explore asymmetric corrective effects in combination with long-term relationships. For example, Hatemi [19] analyzes the integration between the Swedish stock market and the markets of Germany and France before and after joining the EU. Developing markets in contrast to developed markets are not characterized by normal and symmetric distribution of cost of securities. This feature is related to the fact that the agents of the developing markets are more inclined to risk than developed markets' participants. 
Now let us consider the pair of developed countries - developing countries. Today there is no large set of radical new discoveries, and the previous ones already exploited in many ways. High level of economic liberalization is achieved in many developed countries and these achievements are very difficult to be improved further. Moreover, the strengthening of state intervention in the economy is possible (for example, more active government regulation of the financial sector). Thus, the driver of economic growth in developed countries, stimulating entrepreneurship can produce weaker effect than before.

\subsection{The third phase of the cycle "Growth-maturity-decline", applied to the leading economies, and currency asymmetry}

The economic (or business) cycle represents the periodic ups and downs in the economy, fluctuations in business activity. In the past two decades, various approaches to studying the properties of business cycle indicators were carried out by researchers such as Neftchi [20], Luukkonen and Terasvirta [21], Terasvirta and Anderson [22], and Sichel [23]. Basically, these studies focus on asymmetric and non-linear features of business cycles. The idea of asymmetric business cycles is not new in economic theory. In [24], the way how the economy of the certain country behaves differently during the periods of economic growth in comparison with the periods of economic decline according to the asymmetric business cycles is shown. To mitigate possible negative consequences, the correlation of business cycles and degree of susceptibility of countries to asymmetric or symmetric shocks have enormous importance. The asymmetry of the cycle can be manifested in two ways: on one hand by different lengths of the recession-rise vector, and on the other - by different periods of ascent-decline phases. The first feature of asymmetry is the condition for an upward trend in long-term economic growth, and the second one is the result of policy of countercyclical regulation. The results achieved by asymmetric business cycles are far from unanimous: some of them are positive, others are negative. That is, in the phase of crisis and depression there is a certain impulse to the advancing movement of the system forward.

These fluctuations are irregular and unpredictable, so the term "cycle" is quite conditional. It is known that the economy does not develop along the straight line (trend) characterized by economic growth, but through permanent deviation from the trend with its ups and downs. As an example, let us consider the developed economies as we imagine. At present, developed economies are at the "maturity" stage of the "growth-maturitydecline" cycle without any growth prospects. This stage is characterized by large-scale production; the price factor predominates in competitive struggle. The country of innovation already has no competitive advantages that is observed in developed countries, which start moving production to developing countries where labor is cheaper. In developed countries production is also declining, sales markets are concentrated in developing countries and consequently, country of innovation becomes a net importer. There is a new optimal strategy for firms: to produce something that is not relatively cheaper, but what everyone needs.

These changes happen at a turning point when the institutions begin to significantly rebuild for the development and application of new technologies. The cycle goes to the "decline phase", in which productive extensions of the new technology are on the verge of exhaustion, new applications show a diminution of marginal returns, investments are declining and markets are stagnating. Considering the daily development of information technology, features of these phases are still to be determined.

This is natural that such cyclic behavior of economy has consequences for the foreign exchange markets. The same changes of the specific indicator can make different economic senses (so, and financial consequences). These changes depend on the stage of the economic cycle they are observed at. Their expected influences on the exchange rate may be directly opposite, as the financial authorities make regulatory decisions taking into account cyclical behavior of economy. Currency asymmetry and the international hierarchy of currencies are highly stable and constantly reproduced: liquidity and spheres of circulation of dominant and leading currencies increase, whereas penetration of other currencies into foreign markets becomes more difficult. Liberalization of the currency regime and the regime of capital movement strengthens the positions of the dominant and leading currencies: they acquire additional spheres of circulation and sources of growth in liquidity. Domestic currencies lose from liberalization, because in their internal market they compete with stronger monetary units. Fluctuations in the exchange rates of three or four major currencies relative to each other can create new complications. These are key factors for the manifestation of asymmetry, but they are not the only sources of instability in the international financial system.

\subsection{The problem of global poverty}

"All have to feed themselves" - this is the current conventional doctrine that requires an environment that can be adequate to dynamic market. This environment we call "power". The power inevitably arises in economic system. In the conditions of asymmetry (as we see, the fact of its existence in real economy is undoubted) the power becomes unavoidable: the rational individual who is a maximizer "by definition" will not refuse to increase own benefit by using the asymmetry for obedience of other economic agents. The real 
economic world is the world of the unequal (or in our terms, asymmetric) relations. In the economic system, attitudes that include power and coercion dominate. In this sense, not the absence of power, but its presence in relations between economic agents can be considered as a "natural state" of the economic organization of society. If the inequality can be represented in the form of a scale, then at one of its ends will be those who own the greatest number of benefits, and on the other - the least amount of weal. Inequality characterizes society in general, but poverty concerns only part of the population. Depending on how high is the level of country's economic development, poverty covers considerable or insignificant part of the population. Today, many models have been developed, and they can be used to analyze the impact of macroeconomic policies and external shocks on income distribution, employment and poverty. These models provided very detailed specification of the labor market or the main channel through which the macroeconomic shocks and corrective policies influence the economic activity, employment and comparative prices.

Production shocks' impact the poverty asymmetrically and the first possible source of this asymmetry is the fact of waiting for these shocks. The argument is that estimates in forecasting economic prospects may be changed during the business cycle or crises. If current situation develops in economic downturn, a positive industrial shock, for example, induced by fiscal expansion, may have less impact (and therefore less effectiveness) on particular decisions about expenses and investments than during booms. Here, the degree of uncertainty about future profitability is of a great importance. And thus, if production and labor demand become less sensitive to positive shocks, the initial increase in poverty induced by rising unemployment can be difficult to reverse.

Today all the largest cities are located in developing countries. These cities are developing three times faster than cities of developed countries [25]. They are qualitatively different. Looking back, we see that they are driving force of the history. High rates of industrial production of developing countries were achieved primarily due to the relatively small group of countries (so-called core - China, India, Brazil, and Mexico) and the newly industrialized regions. It is also important that these successes have been achieved not only as a result of industrialization, but also largely due to the aforethought transfer (migration) of many large-scale, laborintensive, low-cost and also environmentally hazardous "dirty" industries from North to South.

To all this we can add that the vast majority of large industrial TNCs are concentrated in the North countries, which hold significant part of the industrial potential of the South among other things. The enormous size of rapidly growing Asian economies reduces necessity for developed countries to find markets in developing countries for the realization of economies of scale.

Another factor in the transition from developing countries to the developed is poverty and the increase in the population. Developing countries have an important place in the global community - they account for about $80 \%$ of the population and about $70 \%$ of its territory. They characterize the diversified economy and the duality of the economic structure that on one hand consists of the development of agriculture, and on the other, of crafts and modern industry. In all these countries, there is the dependence of the socio-economic and political development on the world economy, on the sale of their primary products in world markets. Foreign capital takes the key positions in the economy.

The problem associated with the globalization, power and poverty is manifested in the fact that privatization and liberalization of financial markets in the absence of adequate regulatory institutions and banking standards and supervision become the reason for corruption [26]. Russia and other countries of the former Soviet Union can act as a good example. The open capital market in the situation of information asymmetry makes it easier for corrupt leaders to burden their own taxpayers both with the official debt and the debt of the private sector while simultaneously increasing their own accounts in foreign banks. Unregulated markets make it easier to launder money and evade taxes. Global capital markets are not the cause of all these problems, but as a result of global imbalances in the global economy, the asymmetry in the development of poor countries is increasing.

However, the high rate of urbanization, the export of technology and production from the developed world, the fall of the share of employment in agriculture and, accordingly, its enhancing in industry and services, raising level of education and qualifications of the population in poor regions suggest that the poor countries are the main productive forces in the global economy. It should be noted that in the new industrializing countries expenditures on research and development increased significantly. Infectious diseases, transnational crime, and potentially useful, but risky new technologies such as genetically modified foods also involve asymmetric expenses and risks for the poor countries and poor segments of the population. Since the 1980s, they began to move to the formation of mechanism in connection of science and industry, the formation of modern complex of researches and development.

Some major countries in the developing world have a special place by their scientific potential. For example, India is ahead of many middle-income countries by the number of scientific staff and absolute scale of investment in science and researches. 
In developing countries, different institutional arrangements that were undertaken for the development of science and technology in most cases relate to the field of education, local researches in the number of industries and the use of foreign technologies. Often these efforts are weakly connected with the development of the industry. For example, in Mexico, which has the largest R\&D expenditures in the Latin American region, only $1 / 4$ of costs are spent on researches for production purposes.

Developing countries deal with the adaptation of existing technology. Only some of them are the developers in the field of biotechnology, information technology and new service industries. Developing countries cannot easily close their capital markets, and they do not want to, but the benefits of openness also are asymmetric. The companies in developing states prefer to borrow money at banks, but they do not raise funds through sale of shares. The issuance of shares on the capital market requires a higher transparency of companies than of banks. Providing the company with the information about its financial activities is usually problematic. Besides, the narrowness of these capital markets means insufficient number of the institutes (for example, analytical) providing potential investors with information that strengthens vicious circle of information asymmetry. Aubert [17] describes the situation with the application of knowledge of skilled workers in developing countries. The majority of specialists from developing countries who graduated from universities in the US or Europe, upon returning to their homeland, would be responsible for the current situation in their country. They would be faced by the problem of application the gained knowledge. These workers already have poor understanding of the technical, social and cultural environment of their country. The real problem lies in the definition, objectification and patenting of innovations, and then in their commercialization at the national level. Limited resources, the weakness of scientific researchers also do not promote introduction of innovations. Researches in these countries are limited to publications. In this case, the precedent of South Korea and Singapore proved that the role of the state in supporting the business environment and development of new technologies is very significant. First of all, positions of any country in world economy are influenced by position of its producers in the internal and external markets. The ability of developing country to occupy the worthy place in the global economy depends on how quickly its firms manage to occupy attractive niches in the world's commodity and financial markets. Therefore, justification for the economic strategy of any state lies in the plane of analyzing, forecasting and supporting producers, either already having competitive advantages or being able to acquire them in the foreseeable future. Accordingly, the state's ability to support the competitiveness of its producers lays not so much in the sphere of the regulating sectored structure of the economy, as in the regulating conditions for the reproduction of competitive advantages regardless the industry affiliation of producers.

\subsection{Is the IT market a "lemon market"?}

Transition of the world economy to a new technical and economic model of development associated with the widespread use of electronics and computer science poses new challenges, both to separate countries and the developing countries overall. Achieving the modern level of production puts not only the problem of transition economy to machine industry, but at the same times its development on the self-sustaining industrial, scientific and technical basis. Market of information technology and information security is a prime example of market with information asymmetry. The buyer may not know all the details about the selected protection products and their manufacturer is not always eager to share the true information about the quality of his products, as well as about himself. The price of defective means of security is comparable to the best samples of this market, and can be sometimes higher, but with a very flexible approach to the formation of the final value. Thus, we come to the same situation as with the classic "lemons" described by Akerlof [28] - poor-quality means of information protection fill the market, removing upscale remedies, in development and quality testing of which enormous funds were invested. According to Akerlof, many market institutions appear as a result of attempts to solve the problem of asymmetric information. The latter may give rise to the so-called inverse selection. First of all, there is little information about many companies in new industries, such as information technology, while some of those who are delving into the problem (insiders) may have more information about future profitability of such firms. Assessment of stocks of companies that have profitability below average starts to be overstated and they begin to the capital dilution. These companies are starting to release additional shares for new projects more actively than high-yield companies, shares of which are undervalued in the market. As a result, firms with lower profitability grow faster, and the stock market is filled with "lemons". When uninformed investors suddenly discover their mistake, the stock price falls and the information bubble bursts.

In [29] the distribution of competitive Internet technology products in the context of competition between local and transnational corporations is considered. Emphasis is placed on diffuse interactions between technologies influencing the degree of their dominance in electronic markets. Being guided by the existing theories of innovations' distribution and competitive dynamics, the new diffuse model which includes influence of adoption of one technology on distribution of others develops in modern world economy. Ultimately, diffuse processes make it possible to take the dominant position for new technological order in production 
manufacturing. World innovative leaders (the USA, the countries of Europe) generate new knowledge, and the large developing economies (India, China) actively borrow innovations. According to the theory of innovations, technological diffusion is the process of increasing the number of imitators (followers) applying innovation in anticipation of greater profits after the innovator [30]. The western people got used to think that their companies generate the ideas in the laboratories, and then export to developing countries for conducting productions there. This view helps to easier reconcile with the loss of jobs, especially in the manufacturing industries. However, today a lot of things appear far from it. The companies abroad even more often carry out so-called polycentric innovations, organizing the research centers in developing states. And the companies from these countries become the powerful centers of innovations in all areas - from telecommunications to the computer equipment.

Trade between countries may be caused by technological changes occurring in some sectors in one of the trading countries. This country gets a comparative advantage: the new technology allows to produce goods at low cost. If a new product is created, the firm-pioneer has a quasi-monopoly for some time, i.e., receives additional profit.

Currently, the technology is a kernel of many different markets now - from the trivial markets of business and consumer goods to the markets of innovative products with various, and in many cases, fundamental applications. Modernization and diversification of the markets and technologies, competition aggravation in the niche markets, formation of the new segments which are economically perspective and capacious for many companies combating for increase in a market share are the major factors stimulating innovative trends. Market researchers are still far from forming the uniform idea of which technologies make up markets, how they are defined, and whether they experience the same forces as any other market, or they have unique characteristics that require completely different researches, analysis and marketing approaches [31].

As a result of technical innovation between countries, technology gap is formed. This gap will be progressively overcome, because other countries will copy the innovation from country-pioneer. Initially, the two trading countries benefit from innovation, however, with the spread of new technologies less developed countries continues to win, but the more developed the country is losing its advantages.

While innovations play an important role at all stages of development, different types of innovations play various roles at different stages. High technologies based on knowledge-intensive innovations are relevant to the later stages of product development, when it becomes the factor of competitiveness and training, and this allows completing the process of "catching up" [32].

\section{Conclusion}

Developing countries have many times lower labor productivity, and probably many times more modest social achievements than developed ones. Suffice it to point that many of the developing countries still have no pension provision. However, the process of borrowing the achievements of developed countries is conducted in all areas, including technology, and it will only be a positive impact on the economies of developing countries, as now we observe a parade of old (second) technology. High rates of urbanization, the export of technologies and industries from the developed world will gradually reduce poverty. Scientific and technological progress will open wide opportunities for the use of new energy sources and new materials.

How can we forecast changes in the balance of power in this situation? Today the situation is determined not so much by the leading countries, but by many countries catching up. The fact is that any country may "fizzle" and reduce the pace of innovation. This means that for some internal reasons the country may start to degrade, and it will get caught up by the pursuers. This happened repeatedly. For example, Ancient Rome, losing the ability to balance national and private interests, lost economic efficiency, and moved to the prolonged stagnation mode. It is possible that the same fate may befall an alliance of developed countries.

\section{References}

[1] N. G. Mankiw, The macroeconomist as scientist and engineer, Journal of Economic Perspectives, 20(4), 2006, 29-46.

[2] E. Domar, The problem of capital formation, American Economic Review, 38, 1948, 777-794.

[3] Nelson, Theory of the low level equilibrium trap, American Economic Review, 46, 1956, 894-908.

[4] H. Leibenstein, Economic backwardness and economic growth. New York: John Wiley and Sons, 1957.

[5] W. Rostow, The take-off into self-sustained growth, The Economic Journal, 66(261), 1960, $25-48$.

[6] Hirschman, The strategy of economic development. New Haven: Yale University Press, 1958.

[7] J. E. Stiglitz, Freefall: America, free markets, and the sinking of the world economy. New-York: W. W. Norton \& Company, 2010 ISBN: 0393075966

[8] J.-M.Siroën, L'international n'est pas le global: pour un usage raisonne du consept de globalization, Revue d'économie politique, 6, 2004, 681-698.

[9] M. Kacowicz, Globalization, poverty, and the north-south divide, International Studies Review, 9(4), 2007, 565-580.

[10] J. Wheatley, and J. Kynge, Emerging markets: Trading blow. The Financial Times, June 10, 2015

[11] M. Feldstein, The Euro zone's double failure, The Wall Street Journal, 15, 2011.

[12] B. Neuss, Asymmetric interdependence. Do America and Europe need each other?, Strategic Studies, 3(4), $2009,110-124$.

[13] Global Trends 2025: A transformed world. National Intelligence Council, 2010.

[14] E. Balatsky, Temporal model of the intercountry competition, Society and Economy, 2, 2011, 3-20. 
[15] D. Tang, Has the financial integration affected the European Union (EU) trade with the New Member Countries from Central and Eastern Europe (CEEC) during 1994-2013? The Journal of Economic Asymmetries, 13, 2016, 8-20.

[16] Bagnai, and C.A Ospina, "Asymmetric asymmetries" in the eurozone markets gasoline pricing, The Journal of Economic Asymmetries, 13, 2016, 89-99.

[17] R. Luo and N.Visaltanachoti, Real exchange rates, asset prices and terms of trade: a theoretical analysis, Economic Modeling, 27, 2010, 143-151.

[18] T. Athanasios and C. Siriopoulos, Stock markets and industrial production in north and south of Euro-zone: Asymmetric effects via threshold cointegration approach, The Journal of Economic Asymmetries, 12(2), 2015, pp. 162-172.

[19] J. A. Hatemi, P.-O. Maneschiold and E. Rocca, Is the swedish stock market becoming more integrated with those of Germany and France? Working Paper, University of Skovde, Sweden, 2005

[20] S.N. Neftci, Are economic time series asymmetric over the business cycle?, Journal of Political Economy, 92, 1984, 307-328

[21] R. Luukkonen, and T. Terasvirta, Testing linearity of economic time series against cyclical asymmetry, Annales d'Economie et de Statistique, 20(21), 1991, 125-142.

[22] T. Terasvirta, and H.M. Anderson, Characterising non-linearities in business using smooth transition autoregressive models, Journal of Applied Econometrics, 7, 1992, 119-136.

[23] D.E. Sichel, Are business cycles asymmetric: a correction, Journal of Political Economy, 97(5), 1989, 1255-1260.

[24] V. Chirila, and C. Chirila, Testing business cycles asymmetry in Central and Eastern European countries, Modern Economy, 3, 2012, 713-717.

[25] S. Brand, Whole earth discipline: an ecopragmatist manifesto. Viking Penguin, 2009. ISBN 978-0-670-02121-5.

[26] N. Birdsall, Asymmetric globalization: global markets require good global politics, Center for Global Development. Working Paper 12.

[27] J.-E. Aubert, Promoting innovation in developing countries: a conceptual framework, World Bank Institute, World Bank, Washington, DC, 2004

[28] G.A. Akerlof, The market for «lemons»: quality uncertainty and the market mechanism, The Quarterly Journal of Economics, 84, $1970,488-500$

[29] P. Song, Zhang, Y. Cheng, L. Xue, K. Wang and Chenghong Zhang, Asymmetric interaction in competitive internet technology diffusion: implications for the competition between local and multinational online vendors, Journal of Global Information Management, 19(3), 2011, 45-64.

[30] J. A. Schumpeter, The creative response in economic history, Journal of Economic History, 7, 1947, 149-159.

[31] G. John, A.M. Weiss, and Sh. Dutta, Marketing in technology-intensive markets: toward a conceptual framework, Journal of Marketing, 63 (Special Issue), 1999, 78-91.

[32] Innovation for Development 2012, A discussion of the issues and an overview of work of the OECD directorate for science, technology and industry. 